\title{
PENGARUH CAR, NPL, NIM, BOPO, LDR DAN SUKU BUNGA SBI TERHADAP ROA BANK BUMN PERIODE TAHUN 2009-2018
}

\author{
Novia Dini ${ }^{1}$ \\ Gusganda Suria Manda ${ }^{2}$
}

Fakultas Ekonomi Universitas Singaperbangsa Karawang, Jawa Barat, Indonesia ${ }^{1,2}$ Email: novia.dini16203@student.unsika.ac.id ${ }^{1}$ gusganda.suriamanda@fe.unsika.ac.id ${ }^{2}$

\begin{abstract}
This study aims to determine the effect of CAR, NPL, NIM, BOPO, LDR and SBI Interest Rates on ROA of Bank BUMN for the period of 2009-2018. Hypothesis testing of this study uses multiple linear regression analysis. This research was conducted at the BUMN Bank in the period 2009-2018. The research was population is 4 BUMN Bank. The sample technique used in this study is saturated sampel technique. The results showed CAR did not influence ROA, NPL have positive effect on the ROA, NIM have positive effect on the ROA, BOPO have negative effect on the ROA, $L D R$ have negative effect on the ROA, SBI Interest Rate have positive effect on the ROA.
\end{abstract}

Keywords: CAR; NPL; NIM; BOPO; LDR; SBI Interest Rates; ROA.

\begin{abstract}
ABSTRAK
Penelitian ini bertujuan untuk mengetahui pengaruh CAR, NPL, NIM, BOPO, LDR dan Suku Bunga SBI terhadap ROA Bank BUMN periode tahun 2009-2018. Pengujian hipotesisi penelitian ini menggunakan Analisis Regresi Linear Berganda. Penelitian ini dilakukan pada Bank BUMN pada periode tahun 2009-2018. Populasi penelitian sebanyak 4 Bank BUMN. Teknik sampel yang digunakan yaitu teknik sampel jenuh. Hasil penelitian menunjukan CAR tidak berpengaruh terhadap ROA, NPL berpengaruh positif terhadap ROA, NIM berpengaruh positif terhadap ROA, BOPO berpengaruh negatif terhadap ROA, LDR berpengaruh negatif terhadap ROA, Suku Bunga SBI berpengaruh positif terhadap ROA.
\end{abstract}

Kata kunci: CAR; NPL; NIM; BOPO; LDR; Suku Bunga SBI; ROA. 


\section{PENDAHULUAN}

Bank merupakan pilar utama dalam pembangunan sistem perekonomian Indonesia karena perbankan memiliki peran penting sebagai financial intermediary yaitu perantara yang menghubungkan antara yang dimiliki dana ekonomi yang suplus kepada unit ekonomi yang kekurangan bantuan dana (deficit) (Mandasari, 2015). Bank yang beroperasi di Indonesia berdasarkan fungsinya dibedakan menjadi dua fungsi, yaitu Bank Umum dan Bank Perkreditan Rakyat (BPR). Bank umum dibagi menjadi beberapa kelompok antara lain Bank BUMN, Bank Swasta dan juga Bank Campuran. Bank BUMN merupakan salah satu bank yang menopang perekonomian suatu negara karena sebagian modalnya dibiayai oleh kekayaan negara, maka perbankan tersebut harus menjaga kinerja dalam hal profit. Kinerja keuangan bank yang baik mencerminkan bahwa perusahaan tersebut baik. Kinerja keuangan dapat diukur menggunakan profitabilitas, dimana profitabilitas yang digunakan adalah Return On Assets (ROA). Berdasarkan Peraturan Bank Indonesia (2017), ROA dapat diukur dengan membandingkan antara laba sesuadah pajak terhadap total aset (total aktiva). Dimana semakin tinggi nilai ROA maka bank tersebut semakin baik.

Pada tahun 2008 terjadinya krisis keuangan global dimana berawal dari krisis kredit perumahan di Amerika Serikat membuat implikasi pada memburuknya kondisi global secara menyeluruh. Setiap negara baik kawasan Amerika, Eropa, maupun Asia terkena dampak akibat krisis keuangan global tersebut. Salah satu dampak yang terjadi di Indonesia yaitu pada triwulan ke IV tahun 2008, ekonomi makro mengalami penurunan hingga $-3,6 \%$, hal tersebut disebabkan karena 
menurunnya pertumbuhan ekspor barang dan jasa. Tetapi meskipun perekonomian dunia mengalami guncangan yang sangat berat, tetapi ketahanan sektor perbankan di Indonesia masih cukup baik (Bappenas, 2009). Perang dagang yang terjadi pada awal tahun 2018 antara dua negara maju yaitu Amerika Serikat dan China memberikan dampak bagi perekonomian karena dapat menyebabkan perlambatan ekonomi diseluruh negara termasuk Indonesia. Jika dana asing keluar dari pasar keuangan negara, maka menyebabkan mata uang negara tetsebut melemah terhadap dollar Amerika Serikat, termasuk rupiah (Cekaja, 2020). Sama halnya seperti krisis keuangan yang terjadi pada tahun 2008, sektor perbankan Indonesia pada saat terjadinya perang dagang antara Amerika Serikat dengan China masih optimis akan stabil (Kontan, 2020). Berdasarkan Peraturan Bank Indonesia (2017), Bank dapat dikatakan baik apabila nilai Return On Asset berada diatas 1,5\%. Rata-rata nilai ROA bank BUMN berada di atas standar Bank Indonesia yaitu 1,5\%. Berikut ratarata ROA bank BUMN yang terdaftar di Bursa Efek Indonesia periode tahun 20092018:

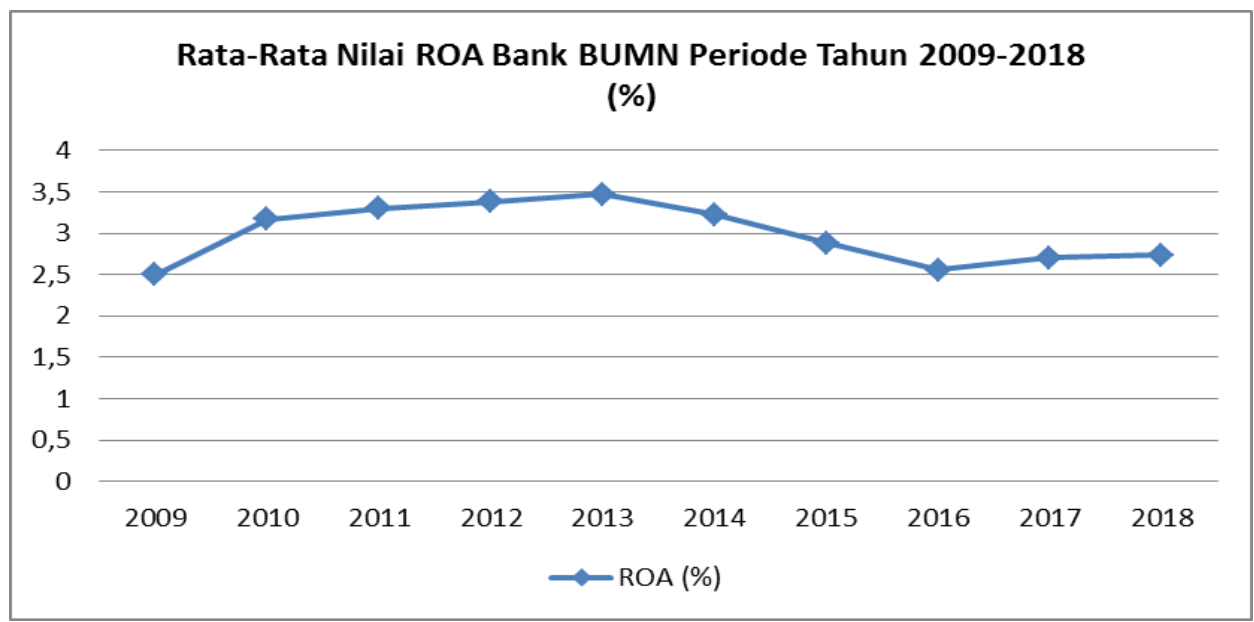

Sumber : Statistik Perbankan Indonesia, data diolah peneliti 2020

Grafik 1.

Rata-rata ROA bank BUMN periode tahun 2009-2018 
Berdasarkan Grafik 1 rata-rata ROA bank BUMN mengalami fluktuatif dan cenderung naik. Tahun 2009 nilai ROA berada di 2,50\%. Tahun 2010-2013 Ratarata ROA bank BUMN mengalami kenaikan secara terus menerus. Pada tahun 2014 ROA mengalami penurunan hingga tahun 2016. Namun tahun 2017 sampai tahun 2018 rata-rata ROA bank BUMN mengalami kenaikan. Tahun 2018 rata-rata ROA sebesar $2,74 \%$.

Terdapat beberapa faktor yang dapat mempengaruhi ROA, diantaranya CAR, NPL, NIM, BOPO, LDR dan suku bunga SBI. Beberapa penelitian terdahulu yang dilakukan oleh Wibowo \& Syaichu (2013); Puspitasari, (2009) menggunakan variabel CAR, NPL, NIM, BOPO, LDR dan suku bunga SBI sebagai mediasi untuk melihat kinerja keuangan bank.

Capital Adequacy Ratio (CAR) merupakan rasio kecukupan modal atau kemampuan bank dalam permodalan yang ada untuk menutup kemungkinan kerugian dalam perkreditan atau perdagangan surat-surat berharga (IBI, 2015:51). Dengan kata lain Capital Adequacy Ratio (CAR) merupakan cerminan dari modal perusahaan untuk memperoleh laba. Berdasarkan Peraturan Bank Indonesia (2017) batas minimal nilai CAR sebesar $8 \%$ dari total aktiva produktif yang dimiliki oleh bank.

Penelitian terdahulu mengenai pengaruh CAR terhadap ROA ditemukan hasil yang tidak konsisten. Penelitian pengaruh CAR terhadap ROA oleh Saputra et al., (2018) menyatakan jika terdapat pengaruh antara CAR terhadap ROA, penelitian yang dilakukan oleh Martini \& Suardana, (2018) menyatakan bahwa CAR berpengaruh positif terhadap ROA. Sedangkan penelitian yang dilakukan oleh 
Wibowo \& Syaichu (2013) menunjukan jika CAR tidak memiliki pengaruh terhadap ROA.

Non Perfoming Loan (NPL) merupakan kredit bermasalah yang terdiri dari kredit yang berklasifikasi kredit kuran lancar, kredit diragukan dan kredit macet (IBI, 2015:309). NPL adalah rasio jumlah total kredit dengan kualitas kurang lancar, diragukan, dan macet terhadap total kredit (Peraturan Bank Indonesia, 2017). Untuk penilaian bank, NPL memiliki nilai maksimum yang ditetapkan oleh Bank Indonesia sebesar 5\%. Kredit bermasalah atau kredit macet yaitu pinjaman yang diberikan bank kepada investor tetapi ketika investor mengembalikan kredit tersebut investor mengalami kesulitan untuk mengembalikannya (Peraturan Bank Indonesia, 2017). Beberapa penelitian mengenai pengaruh NPL terhadap ROA memiliki hasil yang berbeda dan tidak konsisten. Penelitian terdahulu oleh Pinasti \& Mustikawati, (2018) menyatakan bahwa NPL berpengaruh postif terhadap ROA, sedangkan hasil penelitian Harun (2016) menunjukan bahwa NPL berpengaruh negatif terhadap ROA.

Net Interest Margin (NIM) dimana rasio tersebut merupakan perbandingan antara pendapatan bunga bersih terhadap rata-rata aktiva produktifnya (Peraturan Bank Indonesia, 2017). Semakin tinggi NIM yang dimiliki oleh bank menyebabkan meningkatnya pendapatan bunga bersih atas aktiva produktif yang dikelola oleh bank yang bersangkutan sehingga menyebabkan profitabilitas perusahaan meningkat. Beberapa peneliti terdahulu mengenai pengaruh NIM terhadap ROA terdapat hasil yang berbeda-beda. Penelitian oleh Sabir et al., (2012) menyatakan bahwa NIM memiliki pengaruh yang positif terhadap ROA, sedangkan penelitian 
yang dilakukan oleh Dewi (2018) menunjukan bahwa NIM berpengaruh negatif terhadap ROA. Adapun penelitian oleh Oktaviani et al., (2019) mengatakan bahwa NIM tidak berpengaruh terhadap ROA.

Biaya Operasional Pendapatan Operasional (BOPO) merupakan rasio untuk mengukur tingkat efisiensi dan kemampuan bank dalam melakukan kegiatan operasinya (Pandia, 2012). Nilai BOPO rendah mencerminkan bank semakin efisien dalam mengeluarkan biaya operasional bank yang bersangkutan, sehingga kemungkinan terjadi nya masalah semakin kecil. Beberapa penelitian terdahulu mengenai pengaruh BOPO terhadap ROA, memiliki hasil yang berbeda dan tidak konsisten. Penelitian yang dilakukan Sabir et al., (2012) menunjukan bahwa BOPO tidak berepengaruh terhadap ROA, sedangkan penelitian Harun (2016) menunjukan bahwa BOPO berpengaruh terhadap ROA. Penelitian yang dilakukan oleh Wibowo \& Syaichu (2013) menyatakan bahwa BOPO berpengaruh negatif terhadap ROA.

Loan to Deposite Ratio (LDR) merupakan rasio pembiayaan terhadap dana pihak ketiga yang diterima oleh bank (IBI, 2015:55). Semakin besar nilai LDR yang dimiliki oleh bank berarti semakin besar pinjaman yang dimiliki bank hal tersebut menyebabkan profitabilitas bank akan meningkat. Beberapa penelitian mengenai pengaruh LDR terhadap ROA memiliki hasil yang berbeda-beda dan tidak konsisten. Penelitian yang dilakukan oleh Pinasti \& Mustikawati (2018) menyatakan bahwa LDR berpengaruh negatif terhadap ROA, sedangkan penelitian yang dilakukan oleh Dewi (2018) menunjukan bahwa LDR berpengaruh positif terhadap ROA. 
Sertifikat Bank Indonesia atau disingakt SBI adalah surat berharga dalam mata uang rupiah yang diterbitkan oleh Bank Indonesia sebagai pengakuan utang jangka pendek (Bank Indonesia, 2018). Semakin tinggi suku bunga yang ditetapkan oleh Bank Indonesia maka berpengaruh terhadap suku bunga kredit yang menyebabkan terjadinya kenaikan beban bunga dari pinjaman, sehingga pendapatan bunga meningkat, ketika pendapatan bunga meningkat maka laba atau profitabilitas bank akan bertambah. Penelitian yang dilakukan oleh Delsy \& Wiagustini (2014) menunjukan bahwa suku bunga SBI berpengaruh positif terhadap ROA, sedangkan penelitian yang dilakukan oleh Wibowo \& Syaichu (2013) menunjukan bahwa suku bunga SBI tidak berpengaruh terhadap ROA.

Berdasarkan fenomena dan beberapa penelitian terdahulu yang diuraikan di sebelumnya menunjukan hasil yang tidak konsisten. Hal ini menyebabkan ketertarikan penulis dalam melakukan penelitian mengenai "Pengaruh CAR, NPL, NIM, BOPO, LDR dan Suku Bunga SBI terhadap ROA Bank BUMN Periode tahun 2009-2018"

\section{METODE PENELITIAN}

Metode yang digunakan dalam penelitian ini yaitu analisis inferensia. Penelitian dilakukan pada Bank BUMN yang terdaftar di Bursa Efek Indonesia periode tahun 2009-2018. Metode pengumpulan data yaitu dengan menggunakan metode dokumentasi dan studi pustaka. Jenis data adalah data sekunder laporan tahunan 2009-2018 yang diperoleh dari website resmi masing-masing bank dan website Badan Pusat Statistik (BPS). 
Teknik pengumpulan sampel menggunakan sampel jenuh, dimana semua populasi dijadikan sampel. Dalam penelitian ini sampel yang diambil seluruh populasi yaitu Bank BUMN sejumlah 4 bank dengan periode penelitian 2009-2018.

Hipotesis diuji menggunakan analisis regresi linear berganda dengan bantuan SPSS 25. Sehingga didapat persamaan sebagai berikut:

$$
Y=\alpha+\beta_{1} \cdot X_{1}+\beta_{2} \cdot X_{2}+\beta_{3} \cdot X_{3}+\beta_{4} \cdot X_{4}+\beta_{5} \cdot X_{5}+\beta_{6} \cdot X_{6}+e
$$

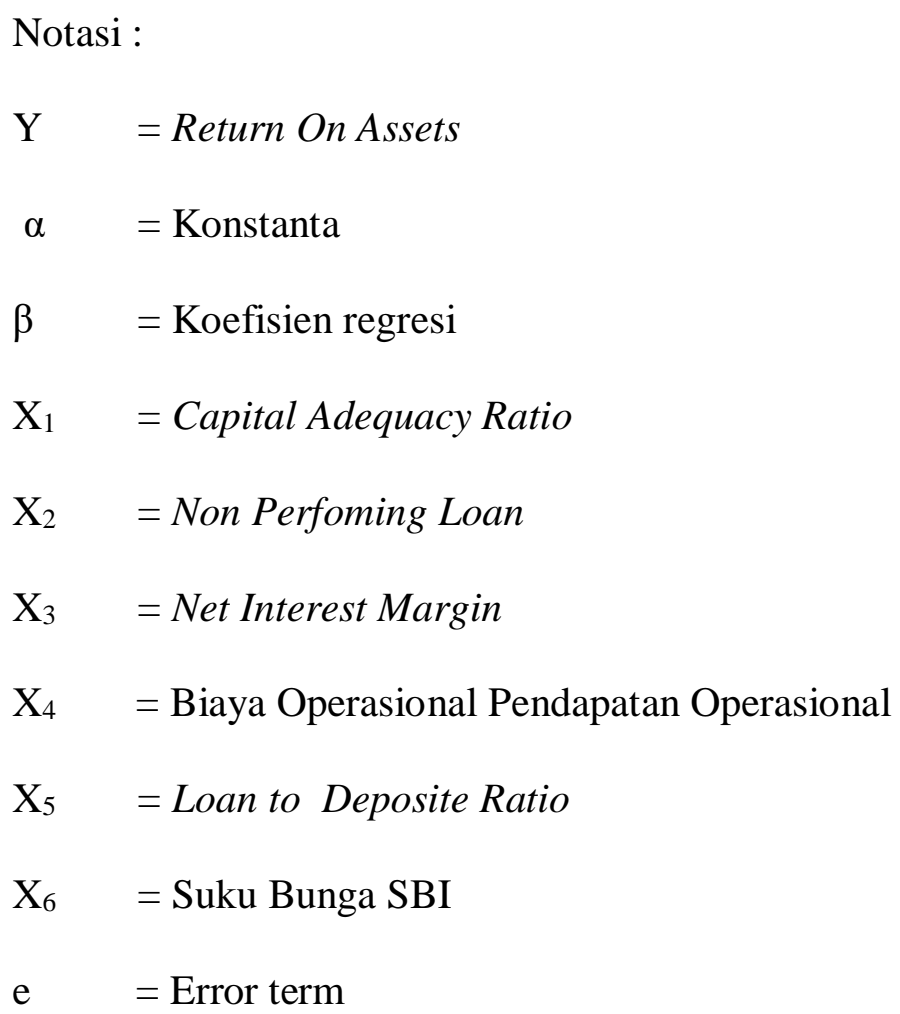

\section{HASIL DAN PEMBAHASAN}

Analisi statistik deskriptif digunakan untuk memberikan gambar mengenai masing-masing varibel penelitian. Berikut Tabel 1 hasil uji analisis deskriptif: 
Tabel 1.

Hasil Analisis Statistic Deskriptif

\begin{tabular}{lccccc}
\hline \multicolumn{1}{c}{ Variabel } & N & Minimum & Maximim & Mean & $\begin{array}{c}\text { Std. } \\
\text { Deviation }\end{array}$ \\
\hline CAR & 40 & 8,30 & 27,70 & 17,85 & 4,49 \\
NPL & 40 &, 32 & 3,52 & 1,41 &, 86 \\
NIM & 40 & 4,32 & 10,77 & 6,35 & 1,52 \\
BOPO & 40 & 59,93 & 88,97 & 73,27 & 7,95 \\
LDR & 40 & 59,15 & 108,80 & 87,03 & 12,78 \\
SUKU BUNGA SBI & 40 & 4,56 & 7,54 & 6,30 &, 95 \\
ROA & 40 & 4,01 & 5,15 & 2,99 & 1,07 \\
\hline
\end{tabular}

Sumber: data diolah peneliti, 2020

Nilai minimum CAR sebesar 8,30\% yang artinya pendapatan terendah CAR sebesar $8,30 \%$ dari total aktiva yang dimilikinya. Nilai maksimum 27,70 artinya pendapatan tertinggi CAR dari total aktiva yang dimilikinya. Rata-rata CAR sebesar 17,85. Standar deviasi CAR sebesar 4,49, nilai standar deviasi CAR lebih rendah dari nilai rata-rata, ini menunjukan bahwa hasil yang baik, karena standar deviasi merupakan cerminan dari deviasi yang rendah, artinya penyebaran data menunjukan kondisi normal.

Nilai minimum NPL sebesar $0,32 \%$ yang artinya pendapatan terendah NPL sebesar $0,32 \%$ dari total kredit yang diberikan. Nilai maksimum 3,52 artinya pendapatan tertinggi NPL dari total kredit yang diberikan. Rata-rata NPL sebesar 1,41. Standar deviasi NPL sebesar 0,86, nilai standar deviasi NPL lebih rendah dari nilai rata-rata, ini menunjukan bahwa hasil yang baik, karena standar deviasi merupakan cerminan dari deviasi yang rendah, artinya penyebaran data menunjukan kondisi normal.

Nilai minimum NIM sebesar 4,32\% yang artinya pendapatan terendah NPL sebesar 4,32\% dari total pendapatan bunga yang dimilikinya. Nilai maksimum 3,52 
artinya pendapatan tertinggi NPL dari pendapatan bunga yang dimilikinya. Ratarata NIM sebesar 6,35. Standar deviasi NIM sebesar 1,52, nilai standar deviasi NIM lebih rendah dari nilai rata-rata, ini menunjukan bahwa hasil yang baik, karena standar deviasi merupakan cerminan dari deviasi yang rendah, artinya penyebaran data menunjukan kondisi normal.

Nilai minimum BOPO sebesar 59,93\% yang artinya pendapatan terendah BOPO sebesar $59,93 \%$ dari total perbandingan biaya operasional terhadap pendapatan operasional. Nilai maksimum 88,97 artinya pendapatan tertinggi BOPO dari total perbandingan biaya operasional terhadap pendapatan operasional. Ratarata BOPO sebesar 73,27. Standar deviasi BOPO sebesar 7,95, nilai standar deviasi BOPO lebih rendah dari nilai rata-rata, ini menunjukan bahwa hasil yang baik, artinya penyebaran data menunjukan kondisi normal.

Nilai minimum LDR sebesar $59,15 \%$ yang artinya pendapatan terendah LDR sebesar 59,15\% dari total kredit dana pihak ketiga yang dimilikinya. Nilai maksimum 108,80 artinya pendapatan tertinggi LDR dari total kredit dana pihak ketiga yang dimilikinya. Rata-rata LDR sebesar 87,03. Standar deviasi LDR sebesar 12,78, nilai standar deviasi LDR lebih rendah dari nilai rata-rata, ini menunjukan bahwa hasil yang baik, artinya penyebaran data menunjukan kondisi normal.

Nilai minimum suku bunga SBI sebesar $4,56 \%$ yang artinya nilai suku bunga terendah yang di tetapkan oleh Bank Indonesia. Nilai maksimum 7,54 yang artinya nilai suku bunga tertinggi yang di tetapkan oleh Bank Indonesia. Rata-rata suku bunga SBI sebesar 6,30. Standar deviasi suku bunga SBI sebesar 0,95 , nilai standar deviasi suku bunga SBI lebih rendah dari nilai rata-rata, ini menunjukan 
bahwa hasil yang baik, artinya penyebaran data menunjukan kondisi normal.

Nilai minimum ROA sebesar 1,14\% yang artinya pendapatan terendah bank sebesar $1,14 \%$. Nilai maksimum 5,15 yang artinya pendapatan tertinggi bank sebesar 5,15. Rata-rata ROA sebesar 2,99. Standar deviasi ROA sebesar 1,07, nilai standar deviasi ROA lebih rendah dari nilai rata-rata, ini menunjukan bahwa hasil yang baik, artinya penyebaran data menunjukan kondisi normal.

Uji normalitas bertujuan untuk menguji apakah dalam model regresi, variabel terikat dan variabel bebas keduanya mempunyai distribusi normal atau tidak. Dalam menguji normalitas penelitian ini menggunakan uji kolmogrofsmirnov dengan kriteria penelitian jika nilai Sig. $(2-t i l e d)>0,05$ maka data tersebut berdistribusi normal. Hasil pengujian nilai Sig. (2-tiled) sebesar 0,069 dan lebih besar dibandingkan dengan 0,05. Hal ini menunjukan bahwa data tersebut berdistribusi normal.

Tabel 2.

Hasil Uji Normalitas

\begin{tabular}{lr}
\hline & Unstandarized Residual \\
\hline $\mathrm{N}$ & 40 \\
Asymp. Sig. (2-tailed) &, $069^{\mathrm{c}}$ \\
\hline Sumber: data diolah peneliti, 2020 &
\end{tabular}

Uji multikolinearitas memiliki tujuan untuk menguji apakah model regresi mempunyai korelasi antar variabel dependen. Melihat ada tidaknya multikolinearitas dalam model regresi dilihat dari nilai tolerance dan lawannya variance inflation factor (VIF). Adapun batas umum untuk menunjukan adanya multikolinearitas jika nilai VIF $<10,00$ maka tidak terjadi multikolinearitas dan jika nilai VIF nya $<10,00$ maka terjadi multikolinearitas. Pada Tabel 3, Nilai VIF untuk 
variabel CAR, NPL, NIM, BOPO, LDR dan suku bunga SBI berada dikisaran 1,493 sampai dengan 5,000 yang artinya nilai kurang dari 10. Maka dapat disimpulkan model regresi bebas atau tidak terjadi multikolinearitas antar variabel independen.

Tabel 3.

\section{Hasil Uji Multikolinearitas}

\begin{tabular}{lccc}
\hline \multirow{2}{*}{ Variabel } & \multicolumn{2}{c}{ Collinearity Statistic } & \multirow{2}{*}{ Keterangan } \\
\cline { 2 - 3 } Tolerance & VIF & \\
Constant) & & & \\
CAR &, 670 & 1,493 & Tidak terjadi Multikolinearitas \\
NPL &, 200 & 5,000 & Tidak terjadi Multikolinearitas \\
NIM &, 214 & 4,680 & Tidak terjadi Multikolinearitas \\
BOPO &, 269 & 3,715 & Tidak terjadi Multikolinearitas \\
LDR &, 418 & 2,393 & Tidak terjadi Multikolinearitas \\
SUKU BUNGA SBI &, 658 & 1,519 & Tidak terjadi Multikolinearitas \\
\hline Sumber: Data diolah peneliti, 2020 & &
\end{tabular}

Sumber: Data diolah peneliti, 2020

Uji heteroskedastisitas memiliki tujuan dalam menguji apakah model regresi terdapat ketidaksamaan variance dari residual suatu pengamatan ke pengamatan laiinya. Model dikatakan baik apabila adanya homoskedastisitas atau tidak terjadi heteroskedastisitas.

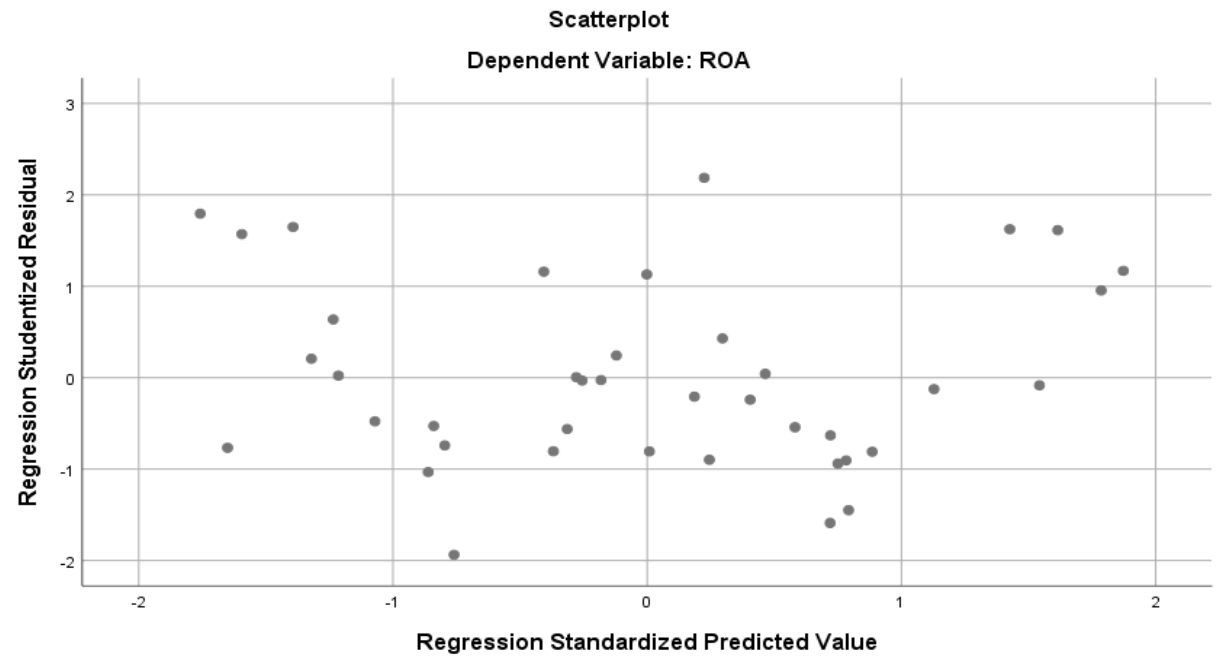

Sumber: Output SPSS 25, 2020

Gambar 1.

Hasil Uji Heteroskedastisitas 
Pada Gambar 1, titik-titik menyebar diatas maupun dibawah angka 0 pada sumbu Y dan tidak membentuk pola yang jelas. Sehingga dapat disimpulkan model regresi dalam penelitian ini bebas dari heteroskedastisitas.

Uji autokorelasi bertujuan untuk menguji apakah dalam model regresi linear berganda terdapat korelasi anatar variabel pengganggu pada periode $\mathrm{t}$ dengan periode t-1. Jika terjadi autokorelasi maka dinamakan problem autokorelasi. Diperoleh hasil nilai DW sebesesar 1,334 dimana nilai DW tersebut berada diantara -2 dampai dengan +2 , berdasarkan Tabel 4 maka dapat disimpulkan data dalam model penelitian ini tidak mengandung autokorelasi.

\section{Tabel 4}

Hasil Uji Autokorelasi

Model Summary ${ }^{b}$

\begin{tabular}{ccccc}
\hline Model & $\mathbf{R}$ & $\begin{array}{c}\mathbf{R} \\
\text { Square }\end{array}$ & $\begin{array}{c}\text { Durbin- } \\
\text { Watson }\end{array}$ & keterangan \\
\hline 1 &, $993^{\mathrm{a}}$ & 0,986 & 1,334 & Tidak terjadi autokorelasi \\
\hline \multicolumn{4}{c}{ Sumber: hasil diolah peneliti, 2020}
\end{tabular}

Tabel 5.

Hasil Uji Regresi Linear Berganda

\begin{tabular}{llrrrrr}
\hline \multirow{2}{*}{ Model } & & \multicolumn{3}{c}{$\begin{array}{c}\text { Unstandardized } \\
\text { Coeficients }\end{array}$} & \multirow{2}{*}{ T } & Sig. \\
\cline { 3 - 4 } & & B & Std. Error & & \\
\hline \multirow{2}{*}{1} & (Constant) & 9,502 &, 566 & 16,792 &, 000 \\
& CAR &,- 007 &, 006 & $-1,115$ &, 273 \\
& NPL &, 265 &, 057 & 4,677 &, 000 \\
& NIM &, 206 &, 031 & 6,611 &, 000 \\
& BOPO &,- 111 &, 005 & $-20,885$ &, 000 \\
& LDR &,- 006 &, 003 & $-2,09$ &, 044 \\
& SUKU BUNGA SBI &, 089 &, 028 & 3,11 &, 004 \\
\hline
\end{tabular}

Sumber: hasil diolah peneliti, 2020 
Hasil persamaan analisis regresi linear berganda sebagai berikut:

Kinerja Keuangan $(\mathrm{Y})=$ 9,502 -0,007 CAR + 0,265 NPL + 0,206 NIM - 0,111

$$
\text { BOPO - 0,006 LDR + 0,89 Suku Bunga SBI }
$$

Berdasarkan persamaan regresi tersebut, maka dapat diinterprestasikan beberapa hal antara lain sebagai berikut: Nilai konstanta $(\alpha)$ sebesar 9,502 bertanda positif. Hal ini menunjukan jika variabel independen sebelumnya atau bernilai 0 maka variabel dependen akan tetap bernilai 9,502. Variabel CAR memiliki nilai koefisien -0,007. Hal tersebut menunjukan jika adanya hubungan tidak searah antara CAR dengan ROA. Artinya setiap pertamabahan CAR sebesar 1 satuan akan mengakibatkan penurunan ROA sebesar 0,007. Variabel NPL memiliki nilai koefisien 0,265. Hal tersebut menunjukan adanya hubungan searah antara NPL dengan ROA. artinya setiap pertamabahan NPL sebesar 1 satuan akan menyebabkan kenaikan ROA sebesar 0,265. Variabel NIM memiliki nilai koefisien 0,206. Hal ini menunjukan bahwa adanya hubungan searah antara NIM dengan ROA. artinya setiap pertamabahan NIM sebesar 1 satuan akan menyebabkan kenaikan ROA sebesar 0,206. Variabel BOPO memiliki nilai koefisien -0,111. Hal ini menunjukan bahwa adanya hubungan tidak searah antara BOPO dengan ROA. Artinya setiap pertamabahan BOPO sebesar 1 satuan akan menyebabkan penurunan ROA sebesar 0,111. Variabel LDR memiliki nilai -0,006. Hal ini menunjukan bahwa adanya hubungan tidak searah antara LDR dengan ROA. Artinya setiap pertamabahan LDR sebesar 1 satuan akan menyebabkan penurunan ROA sebesar 0,006. Variabel suku bunga SBI memiliki nilai 0,089. Hal ini menunjukan bahwa adanya hubungan searah antara suku bunga SBI dengan ROA. Artinya setiap 
pertambahan suku bunga SBI sebesar 1 satuan akan menyebabkan kenaikan ROA sebesar 0,089 .

Dapat dilihat thitung pada setiap variabel penelitian. Dalam membuat kesimpulan menerima atau menolak Ho, harus ditentukan dahulu menggunakan tingkat signifikansi 5\% dan menggunakan uji 2 sisi, diperoleh nilai $\mathrm{t}_{\text {tabel }}(\mathrm{df}=\mathrm{n}-\mathrm{k}$; dua arah $(0,025))$ atau $(\mathrm{df}=40-7=33 ; 0,025)$ di dapat hasil t tabel sebesar 2,03452 atau 2,034.

Nilai t tabel CAR sebesar -1,115 $<2,034$ dengan taraf signifikansi 0,273. Hasil tersebut menunjukan Ho diterima dan $\mathrm{H}_{1}$ di tolak. Maka dapat disimpulkan CAR tidak berpengaruh terhadap ROA.

Nilai $t_{\text {tabel }}$ NPL sebesar 4,677 > 2,034 dengan taraf signifikansi 0,000. Hasil tersebut menunjukan Ho ditolak dan $\mathrm{H}_{2}$ di terima. Maka dapat disimpulkan NPL berpengaruh positif terhadap ROA.

Nilai $t_{\text {tabel }}$ NIM sebesar 6,611 > 2,034 dengan taraf signifikansi 0,000. Hasil tersebut menunjukan Ho ditolak dan $\mathrm{H}_{3}$ di terima. Maka dapat disimpulkan NIM berpengaruh positif terhadap ROA.

Nilai $t_{\text {tabel }}$ BOPO sebesar $-20,885<2,034$ dengan taraf signifikansi 0,000 . Hasil tersebut menunjukan $\mathrm{Ho}$ diterima dan $\mathrm{H}_{4}$ di terima. Maka dapat disimpulkan BOPO berpengaruh nengatif terhadap ROA.

Nilai $t_{\text {tabel }}$ LDR sebesar -2,090 <2,034 dengan taraf signifikansi 0,044. Hasil tersebut menunjukan Ho ditolak dan $\mathrm{H}_{1}$ di terima. Maka dapat disimpulkan LDR memiliki pengaruh positif terhadap ROA. 
Nilai $t_{\text {tabel }}$ suku bunga SBI sebesar 3,110 > 2,034 dengan taraf signifikansi 0,004. Hasil tersebut menunjukan Ho ditolak dan $\mathrm{H}_{1}$ di terima. Maka dapat disimpulkan suku bunga SBI berpengaruh positif terhadap ROA.

Pengujian hipotesis secara simultan dilakukan untuk mengetahui apakah semua variabel inpenden yang ada dalam model mempunyai pengaruh secara bersama-sama terhadap variabel dependen.

Tabel 6.

\section{Uji Hipotesis Simultan}

\begin{tabular}{rrccl}
\hline \multicolumn{1}{l}{ Model } & & F & Sig. & keterangan \\
\hline 1 & Regression & 395,37 &, $000^{\mathrm{b}}$ & berpengaruh \\
\hline
\end{tabular}

Sumber: Data diolah peneliti, 2020

Berdasarkan hasil pengujian secara simultan, yaitu diperoleh nilai $F_{\text {hitung }}$ sebesar 395,37. Adapun nilai $\mathrm{F}_{\text {tabel }}$ pada tingkat signifikansi 5\% dan derajat keabsahan df1 $($ variabel-1 $)=6$ dan df2 $(n-k)=33$ maka Ftabel didapat $F(6 ; 33)=2,39$. Hasil yang diperoleh 395,370 > 2,39 dengan signifikansi 0,000. Sehingga Ho ditolak dan Ha diterima. Dengan demikian terdapat pengaruh antara variabel independen terhadap variabel dependen.

Analisis koefisien determinasi digunakan untuk mengukur seberapa jauh kemampuan model dalam menjelaskan variabel dependen.

Tabel 7.

Hasil uji Determinasi

\begin{tabular}{cccc}
\hline \multicolumn{4}{c}{ Model Summary $^{\mathbf{b}}$} \\
\hline Model & $\begin{array}{c}\text { R } \\
\text { Square }\end{array}$ & $\begin{array}{c}\text { Adjusted R } \\
\text { Square }\end{array}$ & Std. Error of the Estimate \\
\hline 1 &, 986 &, 984 & 0,13726 \\
\hline Sumber: Data diolah peneliti, 2020 & &
\end{tabular}


Nilai koefisien determinasi atau $\mathrm{R}^{2}$ sebesar 0,984 atau $98,4 \%$. Hal ini menunjukan bahwa variabel yang diteliti yaitu variabel independen berpengaruh sebear 98,4\% terhadap variabel dependen. Sedangkan sisanya yaitu 1,6\% dipengaruhi oleh variabel lain yang tidak diteliti dalam penelitian ini.

Pengaruh CAR terhadap ROA. Hasil analisis data membuktikan bahwa CAR tidak berpengaruh terhadap ROA pada Bank BUMN periode tahun 20092018. Hal ini berarti kenaikan ataupun penurunan CAR tidak berpengaruh terhadap ROA. Bank yang memiliki modal yang besar tetapi bank tidak dapat menggunakan modal tersebut dengan efektif maka modal tidak akan berpengaruh terhadap profitabilitas bank. Sehingga kepercayaan masyarakat masih rendah dan masyarakat akan berhati-hati untuk menginvestasikan dananya. Hasil penelitian ini sejalan dengan penelitian yang dilakukan oleh Wibowo \& Syaichu (2013) yang menyatakan bahwa CAR tidak berpengaruh terhadap ROA.

Pengaruh NPL terhadap ROA. Terdapat pengaruh positif antara varibel NPL terhadap ROA pada Bank BUMN periode tahun 2009-2018. NPL merupakan rasio yang mengukur kemampuan manajemen bank dalam resiko kegagalan pengembalian kredit dari nasabah atau debitur. Berdasarkan Peraturan Bank Indonesia (2017) batas maksimum NPL sebesar 5\%. Rata-rata nilai NPL dalam penelitian ini sebesar 1,4148 yang berarti rasio NPL sudah sesuai ketentuan yaitu dibawah nilai maksimum yang ditentukan Bank Indonesia. Kenaikan NPL tidak mengakibatkan penuruna ROA, karena nilai Penyisihan Penghapusan Aktiva Produktif (PPAP) masih dapat menutupi kredit bermasalah. Hasil ini sejalan dengan 
penelitian yang dilakukan oleh Pinasti \& Mustikawati (2018) jika NPL berepengaruh positif terhadap ROA.

Pengaruh NIM terhadap ROA. Terdapat pengaruh positif antara variabel NIM terhadap ROA. Hal tersebut berarti bahwa semakin besar NIM maka akan meningkatkan ROA. NIM merupakan rasio yang menunjukan kemampuan manaejmen bank dalam mengelola aktiva produktifnya dalam menghasilkan pendapatan bunga bersih. Pendapatan bunga bersih meningkat apabila total pendapatan bunga lebih besar dari biaya bunga, yang mengakibatkan laba sebelum pajak meningkat, dan ROA meningkat. Hasil penelitian ini sejalan dengan penelitian yang dilakukan oleh Martini \& Suardana (2018) yang mengatakan bahwa NIM berpengaruh terhadap ROA.

Pengaruh BOPO terhadap ROA. Biaya Operasional Pendapatan Operasional (BOPO) berpengaruh negatif terhadap ROA. Hal ini berarti ketika BOPO meningkat maka efisiensi perusahaan akan menurun dan profitabilitas bank tersebut akan menurun. Tingginya operasional bank menunjukan jika bank tersebut belum mampu menjalankan kegiatan operasionalnya dengan efisien. Sehingga akan berimbas pada penurunan profitabilitas bank. Hal tersebur sesuai dengan teori dimana semakin tinggi biaya operasional bank dibandingkan pendapatan operasional bank maka akan menurunkan profitabilitas bank. Hasil ini sejalan dengan penelitian yang dilakukan oleh Pinasti \& Mustikawati (2018) yang menyatakn bahwa BOPO berepngaruh negatif terhadap ROA.

Pengaruh LDR terhadap ROA. Terdapat pengaruh negatif antara LDR dengan ROA. Bank indonesia telah menentukan batas bawah LDR untuk bank yaitu 
$75 \%$ dan batas toleransi adalah $100 \%$. Dalam menjaga rasio LDR bank harus dapat menjaga dan juga meningkatkan kredit yang diberikan kepada masyarakat, disamping tugas bank sebagai penghimpun dana dari masyarakat. Ketika bank tidak dapat menyalurkan kreditnya ke masyarakat, hal tersebut akan mempengaruhi perolehan laba bank tersebut. Pentaluran kredit yang dilakukan bank dalam jumlah besar akan menyebabkan kredit macet yang tinggi dan berdamoak pada penurunan laba. Hall tersebut sesuai penelitian Dewi (2018) yang menyatakan bahwa LDR berpengaruh negatif terhadap ROA.

Pengaruh suku bunga SBI terhadap ROA. Suku bunga SBI memiliki pengaruh yang positif terhadap ROA. Kenaikan suku bunga SBI yang di tetapkan oleh BI sebagai bank sentral medorong terjadinya kenaikan suku bunga kredit. Dimana jika suku bunga kredit meningkat akan membuat biaya bunga atas pinjaman ikut meningkat, maka pendapatan yang diterima bank dari bunga pinajaman kredit akan ikut meningkat. Jika pendapatan bunga bank naik maka akan meningkatkan laba keuntungan bank. Hasil ini sejalan dengan penelitian yang dilakukan oleh Delsy \& Wiagustini (2014) yang menyatakan suku bunga SBI berpengaruh positif terhadap ROA.

\section{SIMPULAN DAN SARAN}

Berdasarakan analisis pembahasan hasil penelitian yang telah diuraikan sebelumnya, disimpulkan bahwa CAR tidak berpengaruh terhadap ROA, NPL berpengaruh positif terhadap ROA, NIM berpengaruh positif terhadap ROA, BOPO 
berpengaruh negatif terhadap ROA, LDR berepengaruh negatif terhadap ROA, Suku Bunga SBI berpengaruh positif terhadap ROA, dan CAR, NPL, NIM, BOPO, LDR dan Suku Bunga SBI secara simultan berpengaruh terhadap ROA.

Saran untuk perusahaan diharapkan dapat menggunakan modal dengan efektif dan lebih berhati-hati. Perusahaan harus dapat menajaga NPL agar tidak terjadi kredit macet yang tinggi yang menyebabkan laba menurun. Perusahaan harus meningkatkan dan menjaga rasio NIM agar tetap dalam jumlah positif karna hal ini akan menarik investor untuk berinvestasi. Untuk BOPO perusahaan sebaiknya menjaga agar rasio tersebut tetap sesuai ketentuan yang ada. Pemanfaatan dana pihak ketiga berepengaruh negatif terhadap ROA, dalam hal iniperusahaan harus dapat menyalurkan kredit dengan secara berhati-hati agar tidak terjadinya kredit macet. Penentuan suku bunga SBI oleh Bank Indonesia ini sangat berpengaruh terhadap laba Bank, sehingga perusahaan harus tepat dalam menentukan suku bunga kredit agar dapat menaikan laba bank. Saran untuk peneliti selanjutnya diharapkan peneliti selanjutnya mampu menambah tahun penelitian agar dapat hasil penelitian yang lebih akurat. Peneliti selanjutnya hendaknya dapat menambah varibel penelitian yang berpengaruh terhadap Return On Asset Bank.

\section{REFERENSI}

Bank Indonesia. (2018). Peraturan Bank Indonesia Nomor 20/6/PBI/2018 tentang Uang Elektronik. In Bank Indonesia.

Bappenas. 2009. Krisis Ekonomi Global. Retrieve from http://www.bappenas.go.id

Cekaja. 2020. Perang Dagang AS Vs China Dimulai Dampak Versi Bank Indonesia. Retrieve from http://cekaja.com/info/perang-dagang-as-vc- 
china-dimulai-dampak-versi-bank-indonesia/

Delsy, S. R. E., Wiagustini, N. L. P., (2014). Pengaruh Dana Pihak Ketiga, Non Performing Loan Dan Capital. E-Jurnal Ekonomi Dan Bisnis Universitas Udayana. 650-673. https://ojs.unud.ac.id/index.php/EEB/article/view/9777

Dewi, A. S. (2018). Pengaruh CAR, BOPO, NPL, NIM, dan LDR terhadap ROA pada Perusahaan di Sektor Perbankan yang Terdaftar di BEI Periode 20122016. Jurnal Pundi. 1(03). https://doi.org/10.31575/jp.v1i3.55

Hakiim, N., \& Rafsanjani, H. (2016). Pengaruh Internal Capital Adequency Ratio (CAR), Financing To Deposit Ratio (FDR), dan Biaya Operasional Per Pendapatan Operasional (BOPO) dalam Peningkatan Profitabilitas Industri Bank Syariah di Indonesia. Jurnal Aplikasi Manajemen. 14(1), 161-168. https://doi.org/10.18202/jam23026332.14.1.17

IBI. (2015). Bisnis Kredit Perbankan. In Jakarta : PT Gramedia Pustaka Utama

Kontan. 2020. Bank Indonesia (BI): Efek perang dagang menjadi salah satu menurunkan bunga. Retrieve from https://amp.kontan.co.id/news/bankindonesia-bi-efek-perang-dagang-menjadi-salah-satu-alasan-menurunkanbunga

Mandasari, J. (2015). Analisis Kinerja Keuangan dengan Pendekatan Metode RGEC pada Bank BUMN Periode 2012-2013. Jurnal Administrasi Bisnis. Vol 3(2). 363-374. http://ejournal.hi.fisip-unmul.ac.id

Martini, L. K. B., \& Suardana, I. B. R. (2018). Pengaruh Car, Bopo, Ldr Dan Nim Terhadap Roa Dan Perubahan Laba (Studi Pada Seluruh Pada Bpr Di Bali). Juima. 8(1) 64-74. http://ejournal.unmas.ac.id/index.php/juima/article /view/40

Oktaviani, S., Suyono, \& Mujiono. (2019). ANALISIS PENGARUH CAR, BOPO, LDR, NIM DAN UKURAN PERUSAHAAN TERHADAP PROFITABILITAS BANK YANG TERDAFTAR DI BURSA EFEK INDONESIA TAHUN 2012-2017. Bilancia Jurnal Ilmiah Akuntansi. 3(2), 218-231. http://www.ejournal.pelitaindonesia.ac.id/ojs32/index.php/ BILANCIA/article/view/434

Pandia, F. (2012). Manajemen Dana dan Kesehatan Bank. In Manajemen Dana dan Kesehatan Bank.

Peraturan Bank Indonesia. (2017). Surat Edaran Tingkat Kesehatan Bank Umum. Otoritas Jasa Keuangan.

Pinasti, W. F., \& Mustikawati, R. I. (2018). PENGARUH CAR, BOPO, NPL, NIM DAN LDR TERHADAP PROFITABILITAS BANK UMUM PERIODE 
2011-2015. Nominal, Barometer Riset Akuntansi Dan Manajemen. 7(1), 126-142. https://doi.org/10.21831/nominal.v7i1.19365

Puspitasari, D. (2009). Analisis Pengaruh CAR, NPL, PDN, NIM, BOPO, LDR dan Suku Bunga SBI Terhadap ROA (Studi Pada Bank Devisa di Indonesia Perioda 2003-2007)." (Tesis). Semarang: Universitas Diponegoro.

Sabir, M., Ali, M., \& Habbe, A. H. (2012). Pengaruh rasio kesehatan bank terhadap kinerja keuangan bank umum syariah dan bank konvensional di indonesia. Jurnal Analisis. 1(1), 79-86. https://scholar.google.co.id/citations? user=ZUEf41EAAAAJ\&hl=id

Saputra, A., Arfan, M., \& Saputra, M. (2018). PENGARUH CAPITAL ADEQUACY RATIO, NET INTEREST MARGIN, LOAN TO DEPOSIT RATIO DAN NON PERFORMING LOAN TERHADAP PROFITABILITAS BANK UMUM NON DEVISA DI INDONESIA PERIODE 2014-2016. Jurnal Perspektif Ekonomi Darussalam. 4(2), 199212. https://doi.org/10.24815/jped.v4i2.12573

Usman Harun. (2016). Pengaruh Ratio-Ratio Keuangan CAR, LDR, NIM, BOPO, NPL Terhadap ROA Usman Harun. Jurnal Riset Bisnis Dan Manajemen. 4(1), 67-82. https://ejournal.unsrat.ac.id/index.php/jrbm/article/view/12352

Wibowo, E. S., \& Syaichu, M.(2013). ANALISIS PENGARUH SUKU BUNGA, INFLASI, CAR, BOPO, NPF TERHADAP PROFITABILITAS BANK SYARIAH. Diponegoro Journal of Management. 2(2), 10-19. https://ejournal3.undip.ac.id/index.php/djom/article/view/2651 